\title{
EDUCAÇÃO, COMUNICAÇÃO E TECNOLOGIAS: \\ UMA NOVA GEOMETRIA PARA OS DIFERENTES ESPAÇOS EDUCATIVOS
}

\section{Education, Communication and Technologies: a new geometry for different educational spaces}

\author{
Francisco Antonio Pereira Fialho ${ }^{1}$ \\ Elizete Lúcia Moreira Matos ${ }^{2}$
}

\section{Resumo}

Este artigo pretende explorar os conceitos de espaço físico, espaço conceitual e ciberespaço, propondo uma geometria para se compreender como operamos nestes diferentes espaços. A intenção aqui não é a de encontrar respostas, mas o de provocar, nos leitores, reflexões capazes de originar novos artigos sobre o tema abordado.

Palavras-chave: Educação, Espaços de Aprendência, Tecnologias Educacionais.

\section{Abstract}

This article aims to explore the concepts related to a physical, a conceptual, and cyber spaces, proposing a new geometry able to represent how we operate in these different spaces. The intention is not to find answers, but to provoke reader's reflections able to originate other articles about the proposed theme.

Keywords: Education; Learning Spaces; Educational Technologies.

\footnotetext{
Engenheiro e Psicólogo, Mestre e Doutor em Mídias, professor da Pós-graduação em Engenharia da Produção e Gestão do Conhecimento da Universidade Federal de Santa Catarina (UFSC) - Caminho do Travessão, 2913 - Rio Vermelho - CEP 88060-300 Florianópolis, SC.

E-mail: fapfialho@aol.com

2 Pedagoga, Especialista em RH e Psicopedagogia, Mestre em Educação pela PUCPR e Doutora em Gestão e Inovações Tecnológicas pela UFSC. Professora Titular no curso de Pedagogia e Mestrado em Educação - PUCPR - Rua Sanito Rocha, 225, ap. 106 - Cristo Rei - CEP 80050-380 Curitiba, PR.

E-mail: elizete.matos@pucpr.br
} 


\section{Introdução}

"O Modelo deve permitir uma visualização e compreensão adequada e concisa da realidade; a simplicidade dos modelos é um fator a ser considerado, pois facilita a comunicação entre os envolvidos" (SHEER, 1998).

Para Platão "as esferas das idéias se constituía primeiramente nas palavras (logos) e, somente em segunda linha, de imagens (eikon)”. Imagens não eram, para Platão, o resultado da percepção (aisthesis), mas tinham sua origem na própria alma. Para Aristóteles: "O pensamento é impossível sem imagens". (HOELZEL, 1999)

Einstein, certa vez, declarou:

As palavras e a linguagem, escritas ou faladas, não parecem executar função alguma em meu pensamento. As entidades psíquicas que servem de elementos a meu pensamento são certos signos, ou imagens mais ou menos claras que podem ser reproduzidas e combinadas à vontade. (HOELZEL, 1999).

Sistemas de representação são as ferramentas pelas quais construímos modelos para tudo em nossas vidas. Modelos e representações, ao longo desse texto, são sinônimos, significam a forma pela qual compreendemos o mundo que nos rodeia. Educar, nesse sentido, seria o processo pelo qual convertemos situações (de aprendizagem ou não) em conhecimentos. A forma pela qual nos apropriamos do mundo dando a seus elementos voláteis e dinâmicos um significado sempre único.

Nossa intenção, aqui, é a de, como nos ensina mestre Foucault ${ }^{3}$, avançar do "trompe l'oeil", ou seja, de uma visão mais física, em direção ao "trompel'espirit", às questões conceituais envolvidas nos processos de ensino e aprendizagem. Queremos ir mais além e investigar o impacto do virtual, caminhar do material em direção ao abstrato.
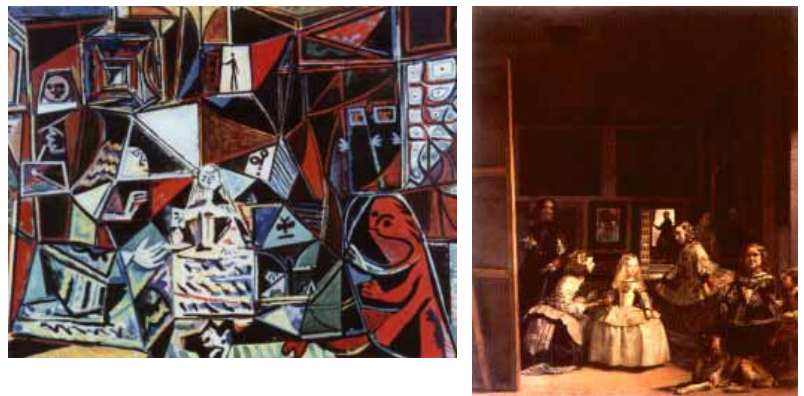

FIGURA 1 - A esquerda uma "cópia" feita por Picasso, Musée Picasso, Barcelone. À direita, Las Meninas de Velásquez, Musée du Prado, Madri, 1656.

Fonte: http://www.yatrides.com/autres/Velasquez_Picasso.htm, Acesso em 19 abr. 2004

\footnotetext{
${ }^{3}$ As Palavras e as Coisas.
} 
Segundo Léa Bustamante (1989), o Conjunto Universo da Geometria é o ESPAÇO e todas as entidades que podemos supor existirem no referido espaço. Axelrod e Cohen (2000) apontam que, além do espaço físico, devemos considerar, ainda, o espaço conceitual. A estes acrescentaremos, ainda, o espaço digital / virtual, o ciberespaço.

O espaço físico é definido pelos autores citados como a localização no espaço geográfico e no tempo de agentes e artefatos. Onde a escola está situada? Que laboratórios, instalações, possui? Quais são os horários de funcionamento, o tipo de cadeiras, etc? Espaço conceitual, por sua vez, seria a "localização", num conjunto de categorias estruturadas, que apontam para a forma com que agentes "próximos" tenderão a interagir.

Por exemplo, ao refletirmos sobre a educação, estamos interessados nas reações, nos comportamentos dos diferentes agentes/atores em relação aos artefatos materiais (leiaute da sala de aula, equipamentos, disposições das mesas, etc.) e abstratos (tipo de aula, expositiva, dialogada, bancária, baseada em resolução de problemas, etc.).

Espaços digitais compreenderiam todas as extensões aos espaços físico e conceitual possibilitados pela tecnologia. O espaço digital daria a medida de nossa conectividade, possibilitando a emergência de novas categorias.

Castells (1999, p.436) trata dessa nova concepção espacial estreitamente relacionada às interações entre indivíduos e grupos de indivíduos: "espaço é o su porte material de práticas sociais de tempo compartilhado...". Sugere, ainda, a existência de um novo modelo espacial característico das práticas sociais que dominam e moldam a sociedade em rede.

Esse espaço, ao qual Castells (1999, p.436)

denomina espaço de fluxos", é por ele diferenciado do espaço físico e do espaço conceitual. Enquanto o espaço físico e conceitual é o suporte material de práticas sociais de tempo compartilhado", o "espaço de fluxos é a organização material das práticas sociais de tempo compartilhado que funcionam por meio de fluxos.

Podemos falar, usando Barthes (1980), no conceito de actantes, em que agentes cognitivos humanos e artefatos não humanos, mas de forma alguma passivos, competem em um mesmo espaço que se virtualiza. Como seria uma Educação que contemplasse esse conceito ampliado de ESPAÇO?

\section{Introduzindo o espaço digital}

O espaço digital não é produto de uma máquina insensível que opera de forma lógica por meio da combinação binária de zeros e uns, mas é construído e reconstruído pelos agentes que interagem com o uso de máqui- 


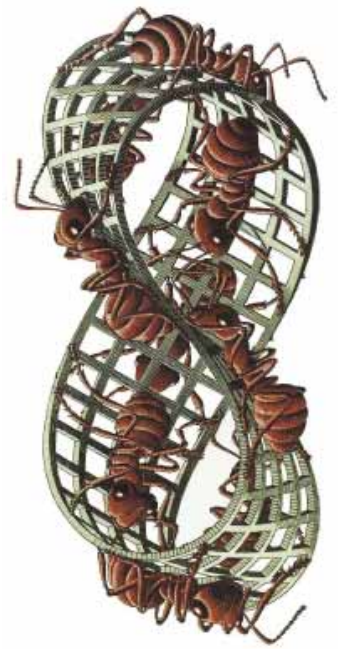

Figura 2 - Quadro de Escher: Moebius Band II

Fonte: http://www.cs.unc.edu/ $\sim$ davemc/Pic/Escher/

nas. Como a mente humana está em constante processo reconstrutivo, o espaço que é por ela construído também tem caráter dinâmico. O espaço digital de fato existe, mas não de forma inerte. Aliás, a ausência de inércia é uma das características desse espaço.

A ação de construir e reconstruir é uma característica do espaço digital. Assim como seus agentes passam por constantes metamorfoses, o espaço passa por seguidas reconstruções, configurando um estado dinâmico e irreversível. A irreversibilidade do espaço se dá pela impossibilidade de seus agentes voltarem a ser o que uma vez foram.

O efeito Moebius também nos remete ao processo co-evolutivo dos sistemas adaptativos complexos, citados por Axelrod, Cohen (2000, p.8), em que sistemas e agentes desenvolvem um contínuo movimento de troca, promovendo a variação de contextos espaciais e dos agentes resultante da ação interativa.

Temos aqui a metáfora do "Libro de Arena" de Borges $(1997)^{2}$ em que todos os actantes (artefatos, agentes) do processo de ensino aprendizagem se transformam. O livro de areia é um

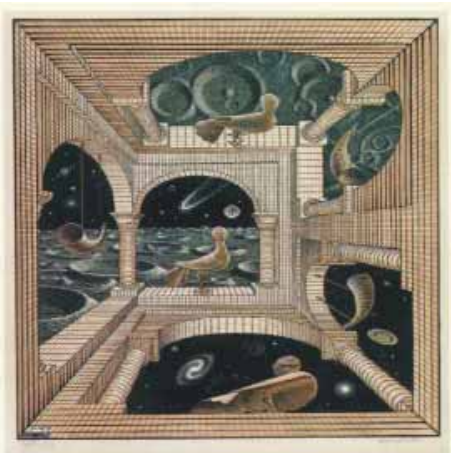
livro mágico que é um novo livro a cada vez que se lê e que nunca tem fim. O genial escritor argentino retrata aqui a INTERNET e os sistemas de conhecimento que Lévy (1996) trata como pertencentes a uma inteligência coletiva.

Lévy (1996, p.20) nos diz ainda de uma reinvenção da cultura nômade em que agentes, graças às novas tecnologias, agora podem interagir em diversos lugares e com grupos diferentes. A distância entre os agentes, que poderia ser uma barreira para as interações, torna-se irrelevante, considerando a velocidade e liberdade com que se pode chegar a qualquer lugar que esteja disponível na rede. Assim como o pensamento humano não encontra barreiras territoriais, o mesmo se observa no espaço digital.

Quando atribuímos ao espaço digital características que evocam dinamicidade interativa, vemos que o espaço deixa de ser apenas um lugar, mas 
assume a posição de processo. A natureza dessa nova sociedade é baseada em conhecimento, organizada em torno de redes e formada a partir de fluxos. Castells (1999, p.423) diz que a 'cidade' informacional não é uma forma, mas um processo. Esse processo é desenhado pelo fluxo de intercâmbios.

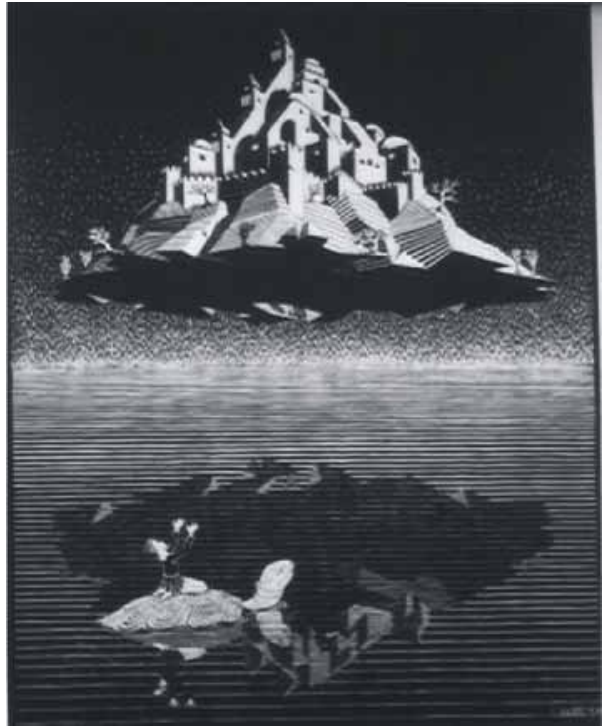

Figura 4 - Two Worlds - Quadro de Escher: Fonte: http://www.cs.unc.edu/ $\sim$ davemc/Pic/ Escher/

mas se faz e refaz incessantemente, continuando atualizável. Lévy (1996) afirma que a mente humana cria constantemente virtualidades, agindo como virtualizadora dessas atualizações.

A escola, hoje, mal e mal explora as possibilidades de enriquecimento do espaço físico com instalações mais modernas e confortáveis. Pior ainda a apropriação do espaço conceitual com aulas ainda bancárias e precárias. O uso do ciberespaço pode ser a saída que buscamos no sentido de reencantar a educação.

Para Moran (2000, p.53), assim como o computador, a Internet pode ajudar a desenvolver a intuição, a flexibilidade e a adaptação a ritmos diferentes. Ela é uma mídia que facilita a motivação pela novidade e variedade de pesquisa que oferece.

\section{Uma Geometria para nossas Representações Mentais}

Projetar e Cortar são as duas únicas operações existentes em Geome- 
tria Projetiva. Projetar consiste em traçar projetantes (retas, planos, etc.) que passem por um centro projetivo (pontos, retas, etc.) que contenham um ente ou elemento real, próprio ou impróprio pertencente à forma ou figura $\mathrm{F}_{0}$ a ser projetada.

Cortar consiste em encontrar um lugar comum a uma figura (geralmente uma reta ou um plano) e uma forma $\mathrm{F}_{0}$. Esse lugar comum é denominado seção, projeção, interseção, ou traço. Esta seção $F_{1}$ resultante é constituída por entes representativos de todos os elementos de $\mathrm{F}_{0}$.

Pertinência é a propriedade que assegura que se um ente pertence a $\mathrm{F}_{0}$, então ele estará representado nas figuras, $\mathrm{F}_{1}$ e $\mathrm{F}_{2}$ resultantes das operações projetivas aplicadas sucessivamente a partir de $\mathrm{F}_{0}$.

Estendendo o conceito de espaço para abranger tanto o espaço físico, como o conceitual e o ciberespaço, passamos a compreender o Centro Projetivo, agora, não apenas como algo físico (ou metafísico, já que ponto, reta e plano também só existem em nossa imaginação), mas como qualquer ontologia capaz de projetar (observar, perceber) e cortar (que passa a ser sinônimo de compreender, construir representações mentais). Os planos de corte com que recortamos a realidade são as crenças, as ideologias as quais nos escravizamos.

Os resultados dessas "operações projetivas" unindo o mundo das idéias ao mundo dos fenômenos são, sempre, algum tipo de representação transitória ou definitiva que reforçam, enfraquecem ou criam alguma nova crença a respeito do mundo.

Santaella e Nöth (1998, p.59) colocam que, "de fato, para a compreensão das diferentes naturezas (palavra-imagem), graus de referencialidade e aptidão comunicativa de toda e qualquer espécie de imagem e quase-imagem, é preciso empreender um retorno a Peirce".

Tomemos a frase de Paulo Freire: Ensinar exige estética e ética. Traduzindo isso em termos de Geometria Projetiva, teríamos:

Quem modela (Paulo Freire)

O que será mode No caso: "ensina1

A frase "ensinar exige estética e ética” é um dos infinitos recortes possíveis da visão de Paulo Freire sobre o ato de ensinar.

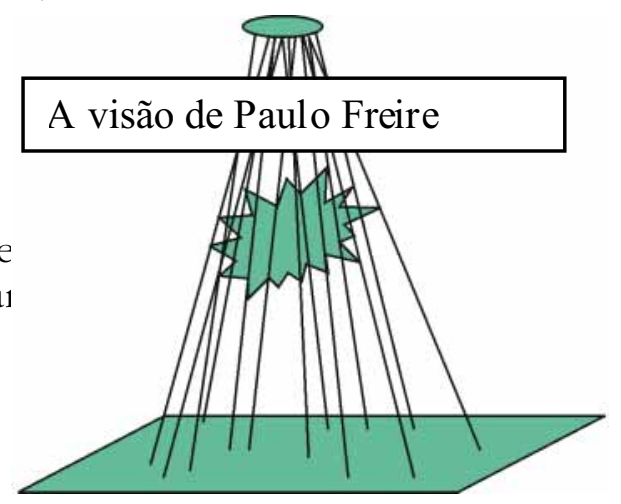

Figura 5- Projetando e recortando idéias Fonte: O Autor 
Lévy (1998), em seu livro Ideografia Dinâmica, cita que, em 1940, Sartre notava que "a imagem não é nem ilustração, nem suporte do pensamento, mas é, ela própria, pensamento, e por isso compreende um saber, intenções".

Se a imagem for o próprio pensamento, já podemos avançar no que diz respeito aos domínios do universo mental em que existiria uma dimensão espelhada do "mundo real" e, ao mesmo tempo, orientadora da percepção deste mesmo mundo.

Fialho (1998) diz que a noção de representação é a mais central em psicologia cognitiva. "É sinônimo de compreensão". Por outro dado, ele também coloca que a representação está longe de ser clara e que, do ponto de vista da sua natureza, deve ser distinguida dos conhecimentos ou crenças.

A semiótica desenvolvida por Charles Sanders Peirce (nascido em Cambridge, Massachussetts, EUA, em 1839 e morto em 1914) coloca-se como uma teoria geral dos signos.

O signo (ou representamen) é o que representa, de alguma forma, algo ou alguém, como, por exemplo, a figura de uma casa ou a foto de uma pessoa.

Quando recebido por um observador (Centro Projetivo), o signo cria, na mente de quem observa, um signo equivalente (Projeção) ou um signo mais desenvolvido de acordo com o repertório e experiências desse observador.

Esse segundo signo que surge na mente do observador é chamado de representante, enquanto que a coisa representada é chamada de objeto.

A partir de um centro projetivo, o olho do espírito, observamos as coisas do mundo e as recortamos de acordo com as crenças que acumulamos ao longo de nossa ontogênese.

\author{
Centro Projetivo \\ Interpretante (Pierce) \\ Referência (O gden-Richards) \\ Sentido (Frege) \\ Intensão (C arnap) \\ D esignatum (M orris, 1938) \\ Significatum (M orris, 1946) \\ Conceito (Saussure) \\ Conotação, connotatum (Stuart M ill) \\ Imagem mental (Saussure, Pierce) \\ Conteúdo (H jelmslev) \\ Estado de consciência (Buyssens)
}
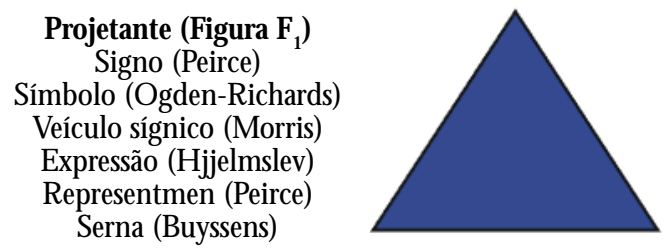

Projeção (Figura $F_{2}$ )

O bjeto (Frege-Peirce)

D enotatum (M orris)

Significado (Frege)

D enotação (Russell)

Extensão (C arnap)

Figura 6- Em busca de uma Geometria Semiótica Fonte: $\mathrm{O}$ autor 
A figura 6 apresenta uma correlação entre a Geometria Projetiva e as diversas propostas advindas a partir da Semiologia de Ferdinand Saussure e da Semiótica de Charles Peirce.

Santaella e Nöth (1998) relatam que Piaget designava imagem mental como imagem interior. Para ele, Piaget (1964, p.97), a imagem interior é uma imitação do mundo exterior trazida à mente por uma função semiótica, e esta função diz respeito à capacidade natural do ser humano de "representar algo através de um signo ou um símbolo ou um outro objeto". Assim, uma imagem interna não é apenas uma cópia passiva da imagem do mundo exterior, mas um produto do que já foi internalizado pela percepção. Também define esta imagem como símbolo "e entende por este, um signo que é distinto de seu significado".

\section{Usando o espaço digital na educação}

Segundo Oliveira et al. (2001), o que confere a um software o caráter educacional, é a sua aplicação no processo ensino-aprendizagem. Temos, neste sentido, duas possibilidades: (PEC).

- Software educativo (SE) ou Programa Educativo por Computador

- Software aplicativo.

Liguori apud Litwin et al.(1997), Cano apud Sancho et a,(1998), Oliveira et al. (2001) e Tajra (2001) classificam os softwares educativos em grandes grupos de acordo com as suas características:

Monitoramento.

- Tutoriais; Exercício ou prática; Demonstração; Simulação; Jogo;

Entre os softwares aplicativos, também chamados aplicações informáticas de base, ou ferramentas de uso polivalente, Cano apud Sancho et al. (1998), Oliveira et al. (2001), Tajra (2001), Liguori apud Litwin et al. (1997) destacam aqueles mais utilizados nos contextos de ensino:

- Editores de texto; Programas de auto-edição; Planilhas eletrônicas; Banco de dados; Editores gráficos.

Entre os softwares aplicativos, Oliveira et al. (2001) destaca, ainda, aqueles que são utilizados na produção de softwares educativos:

- Sistemas de autoria e Ambientes tutoriais. 
A questão que precisamos responder, no entanto, é de como, por meio do emprego das novas Tecnologias, será possível reencantar a educação?

Nossa aposta é que o emprego de metáforas pode subsidiar a criação de Mundos de Aprendizagem em que se explorem os princípios pedagógicos do Lúdico Construtivismo.

Afinal, toda realidade é virtual. A percepção é um processo analógico, cada indivíduo possui uma forma de ver o mundo, reage diferentemente aos estímulos do seu meio, interpreta e interage a sua maneira, possui mecanismos próprios e uma experiência de vida única."Ao conhecer, dar significado às coisas do mundo, o homem cria realidades virtuais que são sempre individuais e indefiníveis. Estas realidades virtuais são metáforas às quais nos ligamos" (FIALHO, 1998).

A Realidade Virtual é criada pelo uso de vários tipos de tecnologias: computação gráfica interativa, holografia, utilização de laser para criação de imagens tridimensionais, visores de cristal líquido, multimídia, dentre outros.

A criação de uma interface em Realidade Virtual envolve um controle tridimensional altamente interativo de processos computacionais. O usuário entra no espaço virtual das aplicações e visualiza, manipula e explora os dados da aplicação em tempo real, usando seus sentidos, particularmente os movimentos naturais tridimensionais do corpo. A grande vantagem desse tipo de interface é que o conhecimento intuitivo do usuário a respeito do mundo físico pode ser transferido para manipular o mundo virtual.

Um sistema de realidade virtual envolve estudos e recursos ligados com percepção, hardware, software, interface do usuário, fatores humanos e aplicações. Para a elaboração de sistemas de computadores de alto desempenho e boa capacidade gráfica, são necessários sistemas paralelos e distribuídos, modelagem geométrica tridimensional, simulação em tempo real, navegação, detecção de colisão, avaliação, impacto social, projeto de interfaces e aplicações simples e distribuídas em diversas áreas.

Os elementos presentes em qualquer sistema de RV são:

Interação: permite ao explorador o controle do sistema; a ausência de interação reduz o sistema a um filme ou vídeo.

Percepção: é o fator mais importante. Alguns sistemas são direcionados diretamente para os sentidos (visão, tato, audição); outros tentam alcançar a mente diretamente, evitando interfaces sensoriais externas e outros sistemas, ainda, recorrem à força da imaginação, permitindo aos seres humanos viverem uma experiência de RV.

Simulação: mundos simulados não têm, necessariamente, que se adaptarem às leis naturais da física. Esta característica faz com que a RV seja aplicável em todas as atividades humanas. 
Segundo Rios (1994, p.2), as características de um sistema de RV são:

Imersão: propriedade que provê o usuário com a sensação de estar dentro de um mundo tridimensional.

Existência de um ponto de observação ou referência: permite a determinação da posição do usuário e situação do mundo artificial ou virtual no qual ele está.

Navegação: propriedade que permite ao usuário mudar seu ponto de observação.

Manipulação: característica que permite a interação e transformação do meio ambiente virtual.

A estas características Fialho et.al. (1997) acrescenta:

Integração: propriedade que provê não somente aos usuários viverem dentro de um mundo tridimensional, mas permite também agentes cognitivos saírem da tela do computador para compartilharem conosco nosso meio ambiente tridimensional "real".

As experiências em primeira pessoa ocorrem quando a interação com o mundo não envolve reflexão da consciência ou uso de símbolos. De acordo com a teoria construtivista, a construção do conhecimento surge das experiências em primeira pessoa, aquelas que nunca podem ser inteiramente compartilhadas (FIALHO, 1998).

A Realidade Virtual Imersiva permite experiências em primeira pessoa pela eliminação de interfaces, que atuam na interação usuário computador. Permite uma experiência que captura a essência do significado para a pessoa, a qual se apresenta para conhecer o mundo (WINN, 1993).

Os sistemas que implementam RV permitem ao usuário a experiência em primeira pessoa de situações as quais, geralmente, no mundo real, o mesmo jamais poderia vivenciar. Por exemplo, podem-se simular reações químicas em reatores e permitir ao usuário "entrar" nas reações de forma a poder ver o processo acontecendo em elementos químicos. O usuário pode entrar em mundos que simulem mundos reais, tais como indústrias e vivenciar situações de perigo, como incêndios, tomar decisões e ver as conseqüências delas. Um aluno pode participar de uma história, dialogando com os personagens, dando sugestões, vivenciando as aventuras e peripécias.

Este tipo de interação torna o aprendizado muito eficiente, permitindo à criança ou adolescente decidir, analisar, concluir, realizar novas tentativas, perceber as conseqüências de suas decisões.

\section{Mundos Virtuais de Aprendizagem}

Um Mundo Virtual pode ser definido como espaços 3D "hiperlinca- 
dos" e navegáveis. Um mundo virtual é um ambiente composto de vários objetos que podem ser a representação do mundo real ou um mundo totalmente novo. Pode-se imaginar a integração educacional virtual do planeta Terra com todas suas diferentes culturas, países, cidades, segmentos de sociedades, e assim por diante (FIALHO et.al., 1997). Cada lugar é projetado considerando alguma metáfora adequada para o modelo mental de seus usuários.

Geralmente o mundo virtual é dividido em múltiplos mundos ou cenários e a aplicação deve prover um meio de o usuário transitar entre os cenários por meio dos Portais (SOUZA, 1997). O armazenamento das informações dos objetos do mundo é a maior parte do projeto de um sistema de realidade virtual, sendo necessário armazenar na base de dados informações sobre os objetos que o habitam, scripts que descrevem as ações dos objetos ou dos usuários (coisas que podem acontecer ao usuário), iluminação, etc.

O usuário pode transportar-se para dentro do mundo virtual por meio de um Avatar ${ }^{4}$, uma espécie de pessoa virtual dentro do mundo. Como Avatares, pessoas que não ouvem podem ouvir, que não enxergam podem ver e as impossibilitadas de andar podem voar como os pássaros (FIALHO, 1997 op.cit.). A utilização desta tecnologia permite uma infinidade de aplicações em todas as áreas do conhecimento, principalmente para a educação.

Além dos Avatares, os mundo virtuais podem ser habitados por agentes cognitivos, que representam personagens nativos destes mundos.

\section{Considerações finais}

$\mathrm{Na}$ pintura linear dos egípcios aos afrescos coloridos dos habitantes dos labirintos de Creta, passamos, sob o olhar de Michel Foucault ${ }^{5}$, do "trompe l'oeil" de Velásquez ao "trompe d'espiri" de Picasso. Mas queremos ir além, queremos nos perder na abstração de Kandinsky, na geometria de Escher, em direção ao virtual e refletir sobre as implicações e imbricações dessas viagens no fazer educação.

Navegar é preciso, viver não é preciso. Segundo Michel Foucault, temos as tecnologias de poder, a análise arqueológica e a análise gen ealógica, como produtoras da subjetividade. Vigiar e punir, disciplinar, rotular o que serve e o que não serve, são produtos de uma construção histórica, de uma visão mecanicista e reducionista do ser humano, que nos amarra ao porto das culturas de massa, impedindo-nos a visão larga do oceano.

Usando as metáforas e os modelos mentais que nos rodeiam, quer

\footnotetext{
4 Avatar é uma palavra muito antiga vinda do Sânscrito que pode ser rudemente traduzida como

"a aparência de Deus na Terra" (DAMER, 1998).

5 As Palavras e as Coisas.
} 
mediado pela cultura, quer pelas diferentes mídias ou, de forma mais profunda, pelas imagens arquetípicas, toda subjetividade nada mais seria do que as representações que fazemos do mundo.

Quando acrescentamos às três dimensões do sensível, as abstrações correspondentes às dimensões imaginárias, as velhas formas mergulharam no mistério, escondendo potenciais antes não imaginados; substituindo a estabilidade eleática por um pulsar ritmado e hermético.

A máquina, ao se inserir como atacante no mundo dos homens, define novos modos de ser em grupo, arrastando a imaginação, que se assusta ante a perplexidade das promessas e ameaças que rondam nosso futuro comum. O ciberespaço com suas estradas psicovirtuais podem, ao mesmo tempo, representar novos caminhos de libertação, ou mega utopias de uma fuga última e definitiva da realidade. Seres da caverna, podemos seguir os "prompts" rumo ao mundo lá de fora, ou perdermo-nos de vez nestes labirintos.

Essa nova dimensão do ser, esta sociedade de idéias que se consubstancia no terreno anárquico da virtualidade das teias que se tecem e se entretecem na metáfora do símbolo, nas abstrações que se materializam em realidades sensíveis, aponta para algo como uma consciência coletiva. O desenho deixa de ser apenas sombras sobre planos e adquire volume, movendo-se graças à animação e aprendendo a aprender graças as redes neuronais e os algoritmos genéticos que imitam o bebê humano.

A capacidade de sonhar, de viajar estrelas e traduzir perfumes são signos da revolta de Anthropos, gritos mudos e suspiros barulhentos, de almas que se recusam à simples racionalidade da lógica simplificadora do sim e do não. Sentir é mais do que pensar.

A máquina traz uma nova possibilidade de expressão que, se bem explorada, pode tornar mais belo o mundo, valorizando o estético, colocando-o, pelo menos, ao mesmo nível do funcional. Cada um pode, agora, criar o ciberespaço em que deseja viver.

\section{Referências}

AXELROD, R. M.; COHEN, M.D. Harnessing complexity: organizational implications of a scientific frontier. New York: The Free, 2000.

BARTHES, R. Elementos de semiologia. São Paulo,SP: Cultrix, 1979.

BORGES, L. E. El Libro de Arena. España: Alianza, 1997.

Bustamante, Léa Transformações Projetivas: sistemas projetivos. 2. ed. Rio de Janeiro,RJ: Edição do Autor, 1989. 
CASTElls, M. A Sociedade em Rede. São Paulo,SP: Paz e Terra, 1999.

DAMER, Bruce. Avatars! exploring and building virtual worlds on the internet. Berkeley, CA: Peachpit, 1998.

DELEUZE, G. O atual e o virtual. In: E. Alliez Deleuze filosofia virtual. (p. 4956). Rio de Janeiro: 34 Literatura S/C Ltda, 1996. Disponível em http:// www.cs.unc.edu/ davemc/Pic/Escher/ Acesso em 19 abr. 2004.

DeleuZe, G.; GuATari, F. Mil Platôs: capitalismo e esquizofrenia. Rio de Janeiro,RJ: Ed. 34, 1995. v. 1.

FIALHO, Francisco A. P. Introdução ao Estudo da Consciência. Curitiba: Gênesis, 1998.

FIALHO, Francisco A. P., CATAPAN, Aracy Hack, CASAS, Luis Alberto Alfaro, et. al. Knowledge Building by Full Integration with Virtual Reality Environments and Its Effects on Personal and Social Life. In: INTERNATIONAL CONFERENCE. Education Technology: asking the right questions. Pennsylvania, USA: Penny State University, 1997.

FOUCAULT, Michel. As palavras e as Coisas: uma arqueologia das ciências humanas. Tradução de Salma Tannus Muchail. 8. ed. São Paulo,SP: Martins Fontes, 1999. (Coleção Tópicos).

HOELZEL, C. G. M. A Imagem como objeto mental. Trabalho acadêmico (Disciplina Ergonomia Cognitiva), 1999. Universidade Federal de Santa Catarina. Disponível em http:/www.eps.ufsc.br/disciplinas/fialho e http:// www.yatrides.com/autres/Velasquez_Picasso.htm, Acesso em 19 abr. 2004.

LÈVY, Pierre. O que é o Virtual? São Paulo,SP: Ed. 34, 1996.

LÉVY, Pierre. A ideografia dinâmica. São Paulo,SP: Loyola, 1998.

LITWIN, Edith. Tecnologia Educacional: política, histórias e propostas, Porto Alegre: Artes Médicas, 1997.

MORAN, J., MASETTO, M., BEHRENS, M. Novas tecnologias e mediação pedagógica. Campinas, Papirus, 2000.

MORIN, E. Ciência com Consciência. Rio de Janeiro,RJ: Bertrand Brasil, 1999. RIOS, Homero Figueroa. Potencial de la Realidad Virtual. Disponível em http://lania.xalapa/spanisch/publications/newleters/fall947index.html Acesso em 19 abr.2004. 
SANCHO, Juana M. Para uma tecnologia educacional. Trad. Beatriz Affonso Neves. Porto Alegre: ArtMed, 1998.

SANTAELLA, Lucia; WINFRIED, Nöth. Imagem: cognição, semiótica, mídia. São Paulo,SP: Iluminuras, 1998.

SCHEER, A.W. Modelagem de processos de negócios. São Paulo,SP: Heidelberg, 1998.

SOUZA, Patrícia C. Sistema de autoria para construção de adventures educacionais em realidade virtual. Florianópolis, 1997. 90 f. Dissertação (Mestrado em Ciência da Computação) - Programa de Pós-Graduação em Ciência da Computação. Universidade Federal de Santa Catarina.

TAJRA, S. F. Informática na Educação: novas ferramentas pedagógicas para o professor na atualidade. São Paulo,SP: Érica. 2001.

WINN, William. A conceptual basis for educational aplications of virtual reality. Disponível em

http://www.hitl.washington.edu/projects/education/winn/winn-R-93-9.txt Acesso em 19 abr.2004. 